\title{
Reliability Monitoring of Laser Scanner Based Navigation
}

\author{
Richard Thum, Josef Borcsok \\ Department of Computer Architecture and System Programming, University of Kassel, Kassel, Germany \\ r.thum@uni-kassel.de, j.boercsoek@uni-kassel.de
}

\begin{abstract}
Autonomous guided vehicles have great advantages over rigidly track-guided conveyor technology, as they can react flexibly to changes in the application area. Temporary obstacles can be easily avoided. The vehicles can circumnavigate bottlenecks and areas at risk of congestion switch to alternative routes. To avoid accidents, safety-relevant position detection is necessary in many areas. The current speed is derived from this driven trajectory and this is safely reduced in the working areas. Minimum distances can also be safely maintained. Therefore it is necessary to permanently control the measured position with regard to disturbance variables and to monitor the reliability of the position detection in real time.
\end{abstract}

Keywords: Autonomous guided vehicle, laser scanner, functional safety, barcode, reliability, failure detection

\section{INTRODUCTION}

Automated guided vehicle systems can be found in many different areas [1], in production areas, in the logistics industry, in large hospitals as well as in particularly dangerous areas such as mining. Raw materials, semi-finished products and finished goods are transported in this way. The advantage over stationary conveyor technology is that no special areas need to be reserved for conveyor technology. Pedestrians, driverless transport systems and transport systems requiring drivers all share the same general traffic areas.

Production plants and logistics centres can be built more compactly and the available space can be used more efficiently. Autonomously driven transport systems are more flexible to changes in material flows in terms of routing, quantity and type of goods to be transported. An increased or reduced need for transport capacity can be adapted by the number of autonomously navigating systems used.

When transporting other objects, only the load handling device needs to be replaced. To save time, this exchange can also be carried out in advance of the transport command on a separate vehicle that is not in use. Should target points be added or modified, this can be done during operation by simply implementing the new target coordinates. Even if the logistics area or production rooms are extended, the target coordinates of the added area must be appended to the system. In case of strong differences in weight or dimensions of the goods to be transported, different vehicles can be used in the system. The time spent by operating and maintenance personnel in hazardous areas, such as foundries, underground mines, can be greatly reduced by using autonomous navigating systems.
A serious disadvantage of using stationary conveyor technology is that the failure generated by a single element of the conveyor chain causes a total failure of the entire line. Autonomously navigating systems can bypass a vehicle that has been taken out of operation by a malfunction. In addition, transport orders of this vehicle can be transferred to another unit. This increases the availability of the entire system. Further advantages are that the same safety-related autonomous navigating systems can operate at high speed in areas without passenger traffic as well as in generally accessible areas reliably without danger at low speed and those individual vehicles can be taken out of service for maintenance work. Nowadays, tactile safety bars have been used for the purpose of damage reduction, which switch off the actuator of the driverless transport system in case of a collision. In addition, laser scanners with programmable protective fields have so far been used to detect obstacles. However, these only have a limited reliable detection range [2].

The operation of autonomous navigation systems moving at high speed in areas with no passenger traffic, as well as the operation of vehicles moving at safely reduced speed in work or maintenance areas, requires precise knowledge of their position with high reliability. A position-dependent assignment of stationary emergency stop switches by the vehicle can be made with reliable and accurate self-localisation of the autonomous navigating system. In addition, minimum distances between vehicles can be specified for each area and safety related maximum speeds can be defined in freely configurable areas. On the basis of the locally necessary safety requirements, the operating conditions can be reliably adjusted according to location. Furthermore, the position of each conveyed material can be continuously tracked and this data can be transferred to a higher-level control system. The whereabouts of goods in the logistics or production area can thus be permanently traced back. In this way running and waiting times in the material flow can be simplified and optimised. 


\section{Position AND ORIENTATion Detection of Vehicles}

A vehicle, shown in blue at Fig. 1, has got a laser scanner [3], [4], which is indicated in orange, and it has got a local coordinate system $\mathrm{x}_{\mathrm{Ve}} / \mathrm{y}_{\mathrm{Ve}}$ (shown in green) [5]. The barcode, which is presented in red [6], [7], includes additional checksums to detect multiple read errors [8]. The right-hand side is detected under the angle $\delta_{1}$ with the distance $\mathrm{d}_{1}$ and the left-hand side is detected under the angle $\delta_{2}$ with the distance $\mathrm{d}_{2}$. Furthermore, the length $\mathrm{L}$ of the barcode, the installation location with its coordinates $\mathrm{x}_{0} / \mathrm{y}_{0}$ and its orientation $\psi_{0}$ are known. Details in the geometric error analysis can be found in [9].

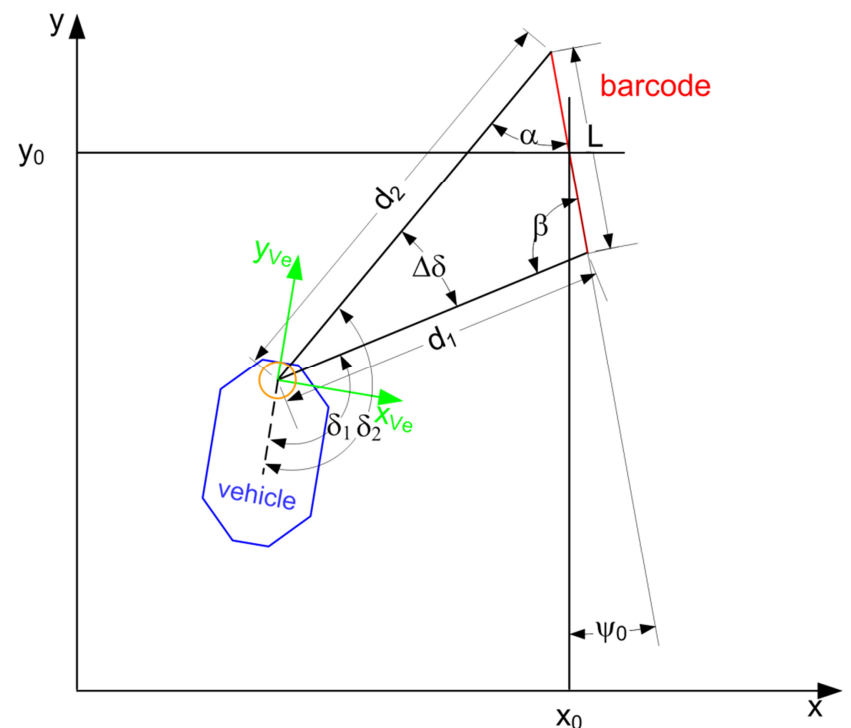

Fig. 1 Detection of a barcode

For general planar triangles the sine theorem applies. The two angles $\alpha$ and $\beta$ can be determined in this way.

\section{INCREASING RELIABILITY OF READING BARCODE CONTENT}

Fig. 2 shows an example of the angle-dependent backscattering of the scanned barcode, which was detected from a distance of about $2.0 \mathrm{~m}$.

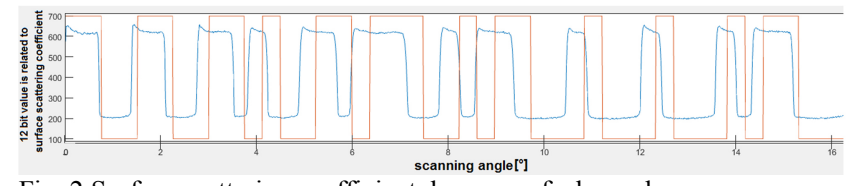

Fig. 2 Surface scattering coefficient due scan of a barcode

After transformation from the polar coordinate system into a Cartesian coordinate system

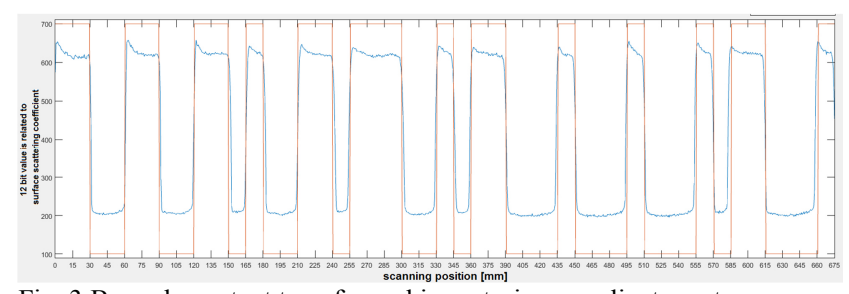

Fig. 3 Barcode content transformed in cartesian coordinate system

In Fig. 3 the grid of possible barcode strip transitions can be seen. If this signal is displayed modulo $15 \mathrm{~mm}$, Fig. 4 is obtained. In the centre of this eye pattern, the signals caused by scattered light from neighbouring barcode strips are lowest. This is the best scanning point. The eye pattern can also be used to analyse the effect of jitter on the signal quality. Multiple sampling, shortly before and after the ideal sampling point, can also reduce the probability of false detection. Here, however, the beam widening, which then acts as a common cause error, must be taken into account.

By checking the distribution of the frequency of occurrence in the upper area and separate ones in the lower area, the type of statistical distribution can be determined. Via the $\chi 2$ test, for example, the hypothesis of a Gaussian distribution can be accepted or rejected.

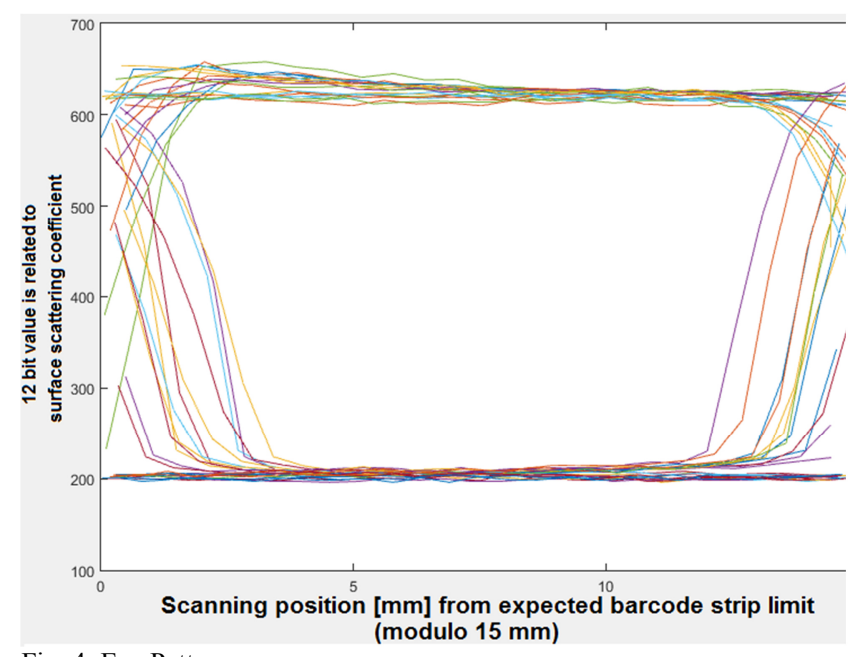

Fig. 4 Eye Patterns

If the $\chi 2$ test is positive, the residual error rate of signal detection can be estimated with a selected limit value. In Fig. 5 the strongly overdrawn variance is shown schematically.

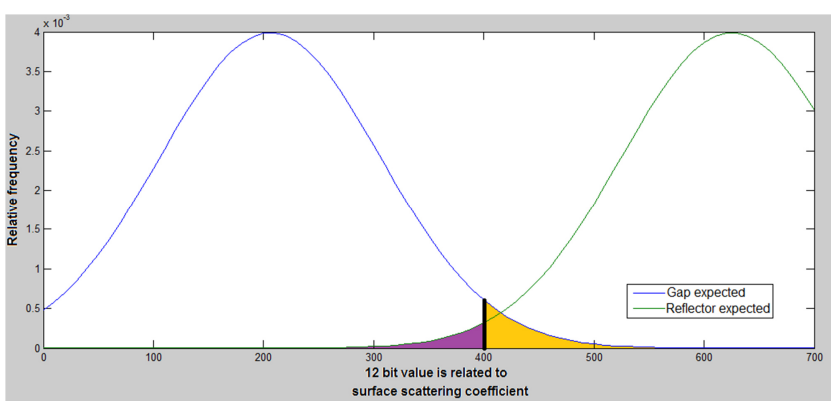

Fig. 5 Probability of false detections 
The false detections 'Gap expected' / 'Reflector detected' are displayed under the orange area and the false detections 'Reflector expected' / 'Gap detected' are displayed under the violet area [9]

The total bit error ratio (BER) with assumed equal frequency of gaps and reflectors results from the mean value of the error detection probability 'gap present', but 'reflector detected' (2) [11] and 'Reflector present' but 'Gap detected (3).

$$
P(X \leq x)=F(x)=\frac{1}{\sigma \sqrt{2 \pi}} \int_{-\infty}^{x} e^{-\frac{1}{2}\left(\frac{t-\mu}{\sigma}\right)^{2}} d t
$$

From (1) results for $(\mathrm{X}>\mathrm{x})$ :

$$
\begin{array}{r}
F_{L}(x)=1-\frac{1}{\sigma_{L} \sqrt{2 \pi}} \int_{-\infty}^{x} e^{-\frac{1}{2}\left(\frac{u-\mu_{L}}{\sigma_{L}}\right)^{2}} d u \\
=1-\frac{1}{2}\left(1+\operatorname{erf}\left(\frac{x-\mu_{L}}{\sigma_{L} \sqrt{2}}\right)\right) \\
=\frac{1}{2}\left(1-\operatorname{erf}\left(\frac{x-\mu_{L}}{\sigma_{L} \sqrt{2}}\right)\right) \\
F_{R}(x)=\frac{1}{\sigma_{R} \sqrt{2 \pi}} \int_{x}^{\infty} e^{-\frac{1}{2}\left(\frac{u-\mu_{R}}{\sigma_{R}}\right)^{2}} d u \\
=\frac{1}{2}\left(1+\operatorname{erf}\left(\frac{x-\mu_{R}}{\sigma_{R} \sqrt{2}}\right)\right)
\end{array}
$$

Equation (4) shows the bit error probability for an individual scan as a function of the detection threshold $\mathrm{x}$, with the same probability of occurrence of reflector strips and gaps. For the bit error rate also the variable $\mathrm{p}$ for the probability can be found in the literature.

$$
B E R=\frac{1}{2}\left(F_{L}(x)+F_{R}(x)\right)
$$

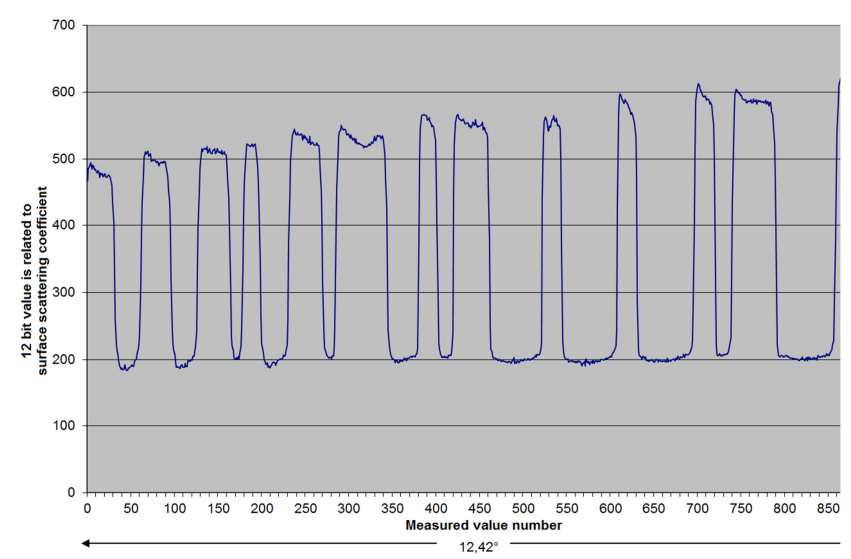

Fig. 6 Backscatter pattern of a inclined detected barcode
Particularly in the case of narrow gaps, an over-radiation of neighbouring barcode retroreflector strips could be observed. Raising the detection threshold therefore improves the reliability of the reading result. Likewise, the backscattering of the laser light is strongly distance-dependent. The light intensity of the backscattered radiation decreases with the square of the distance. Since distance measurement values are available for every single measured value of the backscattered light intensity, a dynamic component can also be included in the generation of the detection threshold. Fig. 6 presents the backscatter values of a $575 \mathrm{~mm}$ long barcode recorded at a distance of $2.0 \mathrm{~m}$ to $2.3 \mathrm{~m}$

The probability of an undetected failure in reading barcode content can be significantly reduced if a CRC is added to the basic information of the barcode. This CRC stored on the barcode is also read out when the barcode is scanned and

\begin{tabular}{|c|c|c|c|c|c|}
\hline \multicolumn{3}{|c|}{ Generator polynomial } & \multirow[t]{2}{*}{$d_{\min }$} & \multirow[t]{2}{*}{$\mathrm{n}$} & \multirow{2}{*}{$\begin{array}{l}\text { Proper } \\
\text { on }\end{array}$} \\
\hline Type & $\begin{array}{l}\text { Hexa- } \\
\text { decimal }\end{array}$ & $\begin{array}{l}\text { Denotation } \\
\text { / Source }\end{array}$ & & & \\
\hline \multirow[t]{3}{*}{$\mathrm{CRC} 24$} & \multirow[t]{3}{*}{ 17B01BD } & \multirow{3}{*}{$\begin{array}{l}\text { CRC-24/6.2 } \\
{[12]}\end{array}$} & 16 & $25 . .26$ & \multirow{3}{*}{$\begin{array}{l}\text { yes } \\
{[12]}\end{array}$} \\
\hline & & & 10 & $27 . .41$ & \\
\hline & & & 8 & $42 . .95$ & \\
\hline \multirow[t]{3}{*}{ CRC16 } & \multirow[t]{3}{*}{$1 \mathrm{~A} 2 \mathrm{~EB}$} & \multirow[t]{3}{*}{$\mathrm{C}_{5}[13]$} & 10 & 18 & \multirow{3}{*}{$\begin{array}{l}\text { yes } \\
{[13]}\end{array}$} \\
\hline & & & 8 & $19 . .27$ & \\
\hline & & & 6 & $28 . .109$ & \\
\hline
\end{tabular}
transmitted to an evaluation unit. In this way, transmission errors are detected in addition to reading errors. By selecting the appropriate user data length and the generator polynomial, several errors occurring simultaneously can be detected [12], [13]. The minimum hamming distance $d_{\text {min }}$ presented their results from the following table

Table 1 Minimum Hamming distances

There is a residual error probability $\mathrm{R}$ when evaluating a barcode reading process of

$$
R\left(p, n, d_{\text {min }}\right)=\sum_{e=d_{\text {min }}}^{n} A_{n, e} p^{e}(1-p)^{n-e}[14]
$$

With the parameters $\mathrm{n}$ (number of all read bits), $\mathrm{p}$ (error probability of the individual bit), $\mathrm{d}_{\text {min }}$ (minimum Hamming distance) and A (binomial coefficients)

If the navigation requires a cyclical read operation, independent sequential individual read operations result in a residual error rate $\Lambda$ per hour of

$$
\Lambda=3600 R v(m-1)[14]
$$

With $v$ (number of read operations / second) and $\mathrm{m}$ (number of communication participants)

To easily separate the individual characters of the barcode, it is advisable to use Code 128 structures from the ISO/IEC 15417 [15] standard. It consists of three stripes and three gaps of different discrete width. Each character has a uniform 
length. Since Code 128 does not support 8-bit characters, fragmentation of the individual bytes is necessary. In the test series, eight bits of user data were used, which were protected with the CRC16 presented in Table 1. Thus, 24 bits of data are to be fragmented. By dividing the data into four six-bit blocks, the individual bits can be mapped into four separate code 128 characters. These four characters are to be regarded as data source in the form of the barcode.

A Black Channel is established between the safety-related data source and the safety-related evaluation unit [14], [16]. To achieve a required safety integrated level (SIL) according to IEC61508-5 [17] during navigation, the value $\Lambda$ must not exceed the limits defined there.

It is assumed that the barcode is applied in one plane surface. Falsifying objects located in front of the barcode can be detected by the laser scanner's distance measurement. This allows additional sources of error to be detected. Reflections of the barcode on optically reflecting surfaces generate a common cause failure. This can result in bit sequences which reduce the minimum hamming distance. The minimum hamming distance is maintained by excluding these individual code combinations

\section{CONCLUSION}

The location and orientation of the barcode itself are referenced via the user data of the barcode. An undetected reading error of this reference number would assign the original coordinates and also the orientation of another barcode. The calculated relative position from Fig. 1 would then be erroneously based on the coordinates of another barcode. Therefore, the barcode content must be determined with an extremely low residual error rate.

It has been shown that when reading a barcode, the probability of reading errors of each individual bit can be determined in real time on the basis of the signal-to-noise ratio of the intensity of the backscattered laser light. Special attention must be paid to the effect of overradiation of narrow barcode gaps in relation to the adjacent retroreflector strips, since overradiation occurs. The distance-dependent backscattering of the laser light must also be taken into account. Additional measures, such as adding a CRC to the user data of the barcode, can be used to detect several simultaneous false detections of individual bits and thus significantly reduce the probability of an undetected misinterpretation of the barcode content.

On the basis of the measurements and the minimum Hamming distance determined via the project planning, a residual error rate $\Lambda$ can be calculated for each barcode reading process. If the residual error rate $\Lambda$ exceeds the permissible limit values for sensors $(0.35 * 10-7$ for SIL3, $0.35 * 10-6$ for SIL2 or $0.35 * 10-5$ for SIL1), unacceptable risks can be prevented by immediately stopping the autonomously navigating system (note: very often a division of the residual error rates into $35 \%$ sensors, $15 \%$ controller and $50 \%$ actuators is suggested).

\section{REFERENCES}

[1] Ullrich G., „Fahrerlose Transportsysteme“, Springer Vieweg, 2nd issue, 2014

[2] Sankaranarayanan Velupillai, Levent Güvenc, "Laser scanners for driver-assisteance system in intelligent vehicles", IEEE Control Systems Magazine 17, April 2009

[3] Yang Chao, Liu Li, Meng Yu,Su Weitao, „Identification of Barcode Beacon and Ist Application in Underground Mining“, $3^{\text {rd }}$ International Conference on Advanced Computer Theory and Engineering (ICACTE), 2010, pp VI-128-132

[4] Luping Fang, Chao Xie, "1-D Barcode Localization in Complex Background", Computational Intelligence and Software Engineering (CiSE), 2010 International Conference on , 2010, pp. 1-3

[5] Thum R., Bichuniak M., Börcsök J., "Laser Scanner Based Position Detection for Safety Related Applications", International Symposium of Fundamentals of Electrical Engineering (ISFEE 2014)

[6] Feng, L.; Anan, L.; Meng, W.; Zhaoxuan, Y.; Robust and Fast Localization Algorithm for Data Matrix Barcode; Optoelectronics and Image Processing (ICOIP), 2010 International Conference on, 2010; pp. 356-359; DOI: 10.1109/ICOIP.2010.299

[7] Houni, K.; Sawaya, W.; Delignon, Y. :Spatial resolution of 1D imagebased barcode reading : an information theoretical approach; Communications, Control and Signal Processing, 2008. ISCCSP 2008. 3rd International Symposium on; pp. 87-92; DOI: 10.1109/ISCCSP.2008.4537198

[8] Thum R., Bichuniak M., Börcsök J., "Safety Related Position Detection via Odometry and Laser Scanner", $12^{\text {th }}$ International Conference on Circuits, Systems,Electronics, Control \& Signal Processing (CSECS'13), pp. 294-298

[9] Thum, R.; Börcsök, J.: Error Detection on Precise Laser Scanner Based Navigation; 2015 XXV International Conference on Information, Communication and Automation Technologies (ICAT) October 29 October 31, 2015, Sarajevo, Bosnia and Herzegovina; DOI: 10.1109/ICAT.2015.7340530

[10] Börcsök, J.; Hannen, H.: Determination of Bit Error and Residual Error Rates for Safety Critical Communication; Systems, 2007. ICONS '07. Second International Conference on; pp. $39-44$; DOI: 10.1109/ICONS.2007.21

[11] Bronstein, I.; Semendjanew, K.; Musiol, G.; Mühling, H.: Taschenbuch der Mathematik für Ingenieure und Studenten; Harri Deutsch; Frankfurt; 6. Vollständig überarbeitete und ergänzte Auflage 2005; ISBN: 978-38171-2006-2; Seite 780 / Gl. 16.70a

[12] Castagnoli, G.; Braeuer, S.; Herrman, M.: Optimization of Cyclic Redundancy-Check Codes with 24 and 32 Parity Bits; IEEE Transactions on Communications; Volume: 41, Issue: 6, pp. 883-892; DOI: $10.1109 / 26.23191$

[13] Baicheva T., Dodunekov S., Kazakov P.; Undetected error probability performance of cyclic redundancy-check codes of 16-bit redundancy; IEE Proceedings - Communications; Volume: 147, Issue: 5; Pages: 253 - 256; DOI: 10.1049/ip-com:20000649

[14] IEC 61784-3:2007: Industrial communication networks - Profiles - Part 3: Functional safety fieldbuses - General rules and profile definitions; International Electrotechnical Commission (IEC); Geneva, Switzerland

[15] IEC/ ISO 15417: Information technology -- Automatic identification and data capture techniques - Code 128 bar code symbology specification; Edition 2; International Electrotechnical Commission, Geneva Switzerland; 2007

[16] Börcsök, J.: "Functional Safety: Basic Principles of Safety related systems", Hüthig publishing company,Heidelberg, Germany 2007

[17] IEC 61508 edition 2-5: Functional safety of electrical/ electronic/ programmable electronic safety-related systems - Part 5: Examples of methods for the determination of safety integrity levels (IEC 615085:2010); International Electrotechnical Commission, Geneva Switzerland; 2010

\section{Creative Commons Attribution License 4.0 (Attribution 4.0 International, CC BY 4.0)}

This article is published under the terms of the Creative Commons Attribution License 4.0

https://creativecommons.org/licenses/by/4.0/deed.en_US 